\title{
INCLUSÃO, DIVERSIDADE E IGUALDADE NA CONAE 2010: PERSPECTIVAS PARA O NOVO PLANO NACIONAL DE EDUCAÇÃO
}

\author{
Adriana Lia Friszman Laplane* \\ Rosângela Gavioli Prieto**
}

\begin{abstract}
RESUMO: No presente texto são exploradas as principais propostas que compuseram o "Eixo VI - Justiça Social, Educação e Trabalho: Inclusão, Diversidade e Igualdade" na Conferência Nacional de Educação (CONAE), em 2010. O objetivo é apresentar uma visão panorâmica sobre os temas deste eixo e suas implicações para a formulação do novo Plano Nacional de Educação (PNE). A análise dos documentos preparatórios para o PNE mostra que, durante a última década, houve aumento de visibilidade dos temas do Eixo, o que reflete na sua presença maciça na formulação de princípios e metas educacionais para a próxima década.
\end{abstract}

Palavras-chave: Educação especial. Plano Nacional de Educação. Política educacional. Inclusão escolar. CONAE 2010.

INCLUSION, DIVERSITY AND EQUALITY IN THE 2010 CONAE: PERSPECTIVES FOR THE NEW NATIONAL PLAN FOR EDUCATION

ABSTRACT: This paper explores the main proposals for the " 6 " Axis - Social Justice, Education and Work: Inclusion, Diversity and Equality" of the National Conference on Education 2010. It presents a panoramic view of these themes and their implications on the redaction of the new National Plan for Education. The analysis of the preparatory documents for the new National Plan

* Doutora em Educação e professora da Faculdade de Ciências Médicas da Universidade Estadual de Campinas (uniCAMP).E-mail: adrifri@fcm.unicamp.br

** Doutora em Educação e professora da Faculdade de Educação da Universidade de São Paulo (USP). E-mail: rosangel@usp.br 
for Education shows that, these last ten years, the $6^{\mathrm{TH}}$ Axis topics have gained visibility, leading to their increasing presence in the formulation of educational principles and aims for the next decade.

Key words: Special education. National Plan for Education. Educational policy. School inclusion. 2010 National Conference on Education.

\section{Introdução}

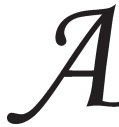

Conferência Nacional de Educação (CONAE), em 2010, mobilizou, em âmbito nacional, diferentes segmentos da sociedade em torno da discussão de diretrizes e estratégias, com vistas a consolidar "marcos para a construção de um novo Plano Nacional de Educação” (CONAE, 2010a, p. 14).

O tema central da CONAE 2010 - "Construindo o Sistema Nacional Articulado de Educação: Plano Nacional de Educação, diretrizes e estratégias de ação" - em si já anuncia algumas de suas tarefas. Nos documentos da Conferência, os argumentos apregoam a mobilização nacional pela qualidade e valorização da educação, na perspectiva da inclusão, da igualdade e da diversidade, e apresentam a sistematização das propostas para políticas de Estado que expressem a efetivação do "direito social à educação com qualidade para todos" (CONAE, 2010a, p. 13, Item 8; CONAE, 2010b, p. 12). Destacam, também, a necessidade de que sejam garantidas as relações entre as políticas educacionais e outras políticas sociais.

Entre as "grandes bandeiras" da CONAE 2010 encontra-se a de fortalecer as medidas de inclusão, com diferentes adjetivaçôes ("social", "no processo educacional", "de pessoas com deficiência”, "digital”), associando-as ao fim das desigualdades sociais e das educacionais ou a igualdade social, qualidade de vida e qualidade social.

Apesar da indiscutível relevância social desse eixo, não é possível deixar de registrar a exorbitância de temas nele reunidos, pois neste se somaram: "Relações étnico-raciais"; "Educação especial"; "Educação do campo"; "Educação indígena"; "Educação ambiental", "Gênero e diversidade sexual", "Crianças, adolescentes e jovens em situação de risco", "Formação cidadã e profissional" e "Educação de jovens e adultos". De 
fato, como o próprio material subsidiário da Conferência analisa, "cada um deles [tem] com especificidades históricas, políticas, de lutas sociais e ocupam lugares distintos na constituição e consolidação das políticas educacionais" e, "além disso, realizam-se de forma diferenciada, no contexto das instituiçôes públicas e privadas da educação básica e da educação superior" (CONAE, 2010a, p. 105, item 254). Pode-se, sem muito auxílio analítico, antever que a discussão de cada proposta dos referidos temas foi absolutamente prejudicada pela própria organização do eixo. Assim, muitas propostas foram referendadas por uma dinâmica movida muito mais pelo sentido de reconhecimento do processo de construção das reivindicaçôes de cada segmento representado nas plenárias, do que pela discussão aprofundada de algumas destas.

Subsidiado por esses pressupostos sobre os objetivos e organização da CONAE, este trabalho apresenta, primeiramente, aspectos relacionados à transversalidade do Eixo VI, assinalando a presença de itens correspondentes a este nos demais eixos. A seguir, traça um panorama das propostas para os diferentes temas abordados no Eixo VI e, finalmente, apresenta as perspectivas em relação à formulação do novo Plano Nacional de Educação (PNE).

\section{Transversalidade do Eixo VI}

O Documento Final da CONAE (2010b) abarca seis eixos, sendo que, nos cinco primeiros, nota-se a menção constante de tópicos que dizem respeito ao Eixo VI.

O primeiro Eixo, ao discorrer sobre o "Papel do Estado na garantia do direito à educação de qualidade: organização e regulação da educação nacional", faz referência à injustiça, à desigualdade e à exclusão social e aos seus reflexos na educação (idem, ibid., p. 29). Algumas propostas abordadas neste Eixo tangenciam de forma clara as preocupações do Eixo VI e são explicitadas nos seguintes itens: "i. direito à formação integral, por meio da garantia da universalização, da expansão e da democratização com qualidade, da educação básica e superior"; "iii. estabelecimento de políticas de educação inclusiva, visando à superação das desigualdades educacionais vigentes entre as diferentes regiōes, contribuindo com o desenvolvimento econômico, social e cultural do País"; "iv. reconhecimento e valorização da diversidade, com 
vistas à superação das desigualdades sociais, étnico-raciais, de gênero e de orientação sexual, bem como atendimento aos deficientes"; "v. valorização da educação do campo, quilombola e escolar indígena a partir de uma visão que as articule ao desenvolvimento sustentável” (p. 37). Cita, ainda, os "princípios da universalização, da qualidade social da educação e do direito à diversidade, bem como da democratização de sua gestão" (p. 38).

O "Eixo II - Qualidade da Educação, Gestão Democrática e Avaliação" destaca a "inclusão em todas as dimensões, níveis, etapas e modalidades", como princípio fundamental (CONAE, 2010b, p. 41). Neste Eixo, a qualidade da educação não pode ser definida sem a "dimensão socioeconômica e cultural", a "heterogeneidade" e a "pluralidade sociocultural”, as quais devem ser consideradas nos planos, projetos políticopedagógicos e currículos (idem, ibid., p. 47). A formação deve, entre outros, "estar em sintonia com as políticas públicas de inclusão, de resgate social e do mundo do trabalho".

Os diferentes recursos para garantir "as condições de acessibilidade e atendimento para pessoas com deficiência”, assim como o acesso e as condiçốes de permanência se vinculam às ações relacionadas:

(...) à diversidade socioeconômica, étnico-racial, de gênero e cultural e à garantia de desempenho satisfatório dos/das estudantes; no caso dos estudantes com deficiência, acompanhamento por profissionais especializados, como garantia de sua permanência na escola e a criação e/ou adequação de espaços às suas condições específicas, garantida pelo poder público. (p. 52)

No que se refere à avaliação, esta deve levar em consideração "os impactos da desigualdade social e regional", "os contextos culturais" e, também, "contribuir para a formação e valorização profissional" (p. 54), entre outros fatores que incidem na aprendizagem.

Finalmente, por meio da gestão democrática será possível consolidar uma política que contemple "a diversidade cultural, étnico-racial, de gênero, do campo" e, para isso, observa-se a necessidade de dialogar com os movimentos sociais (de negros/as, quilombolas, índios, mulheres, do campo e outros) (p. 57).

O Eixo III aborda a "Democratização do Acesso, Permanência e Sucesso Escolar" e remete à 
(...) democratização do acesso e das condições de permanência adequadas aos/às estudantes no tocante à diversidade socioeconômica, étnico-racial, de gênero, cultural e de acessibilidade, de modo a efetivar o direito a uma aprendizagem significativa, garantindo maior inserção cidadã e profissional ao longo da vida. (CONAE, 2010b, p. 65)

Dentre as várias questōes que o terceiro Eixo considera como fundamentais, destacam-se a crítica ao "dualismo estrutural entre o ensino médio e a educação pública profissional" e a "ampliação das oportunidades educacionais, bem como a melhoria da qualidade de ensino para essa etapa da educação básica, inclusive na modalidade de educação de jovens e adultos", posto que estas duas modalidades de ensino são abordadas no Eixo VI, foco deste trabalho (idem, ibid., p. 69; grifos do original). Menciona-se, também, a necessidade de expandir a

(...) educação pública profissional de qualidade, entendida na perspectiva do trabalho como princípio educativo, com financiamento público permanente que atenda às demandas produtivas e sociais locais, regionais e nacionais, em consonância com a sustentabilidade socioambiental e com a inclusão social. (p. 70)

Da mesma forma, neste Eixo são defendidas a "consolidação de uma política de educação de jovens e adultos" e a garantia de "oferta e condições de continuidade de escolaridade no sistema público de ensino" (p. 70; grifos no original), assim como:

A implementação efetiva de uma política educacional como garantia da transversalidade da educação especial na educação, seja na operacionalização desse atendimento escolar, seja na formação docente. Para isso, propõe-se a disseminação de política direcionada à transformação dos sistemas educacionais em sistemas inclusivos, que contemplem a diversidade com vistas à igualdade, por meio de estrutura física, recursos materiais e humanos e apoio à formação, com qualidade social, de gestores e educadores nas escolas públicas. Isso deve ter como princípio a garantia do direito à igualdade e à diversidade étnico-racial, de gênero, de idade, de orientação sexual e religiosa, bem como a garantia de direitos aos alunos com deficiência, transtornos globais do desenvolvimento e altas habilidades/ superdotação. (p. 71; grifos do original)

Devem ser ofertadas a educação básica de qualidade, a inclusão e a permanência de todos/as no processo educacional no ensino regular. 
Inclusão, diversidade e igualdade na CONAE $2010 \ldots$

Esse item diz respeito à educação especial, educação de jovens e adultos, educação escolar indígena, educação de afrodescendentes, educação do campo, educação profissional e educação ambiental (p. 72). Deve ser estendida a gratuidade em cursos e programas de educação profissional e deve-se ampliar o número de vagas em cursos técnicos para estudantes de baixa renda (p. 73). No que se refere à educação superior, é citada a necessidade de "políticas públicas de inclusão social dos/das estudantes trabalhadores/as (...)" e "(...) a efetivação de ações afirmativas para o acesso e permanência de grupos sociais e étnico-raciais com histórico de exclusão e discriminação nas instituiçõos de ensino superior brasileiras". O último item do Eixo III finaliza com uma proposta cabível no Eixo VI:

Compreender a educação das relações étnico-raciais e a discussão sobre igualdade de Gênero, com políticas de ações afirmativas voltadas a ambos, como fundamentais à democratização do acesso, à permanência e ao sucesso em todos os níveis e modalidades de ensino. (CONAE, 2010b, p. 74; grifos no original)

O Eixo IV se refere à "Formação e Valorização dos Profissionais da Educação" e afirma a necessidade de se garantir a presença da concepção de educação inclusiva, na formação inicial e continuada de professores, o que pressupóe a incorporação do respeito às diferenças e o reconhecimento e a valorização da diversidade (CONAE, 2010b, p. 82). Prevê a formação inicial e continuada aos profissionais atuantes em educação de jovens e adultos; educação do campo; professores/as indígenas, ciganos, quilombolas, populaçôes tradicionais e demais etnias (idem, ibid., p. 8889) e também a implementação de programas que discutam outros temas expressivos das diferenças, destacando o combate a todas as formas de discriminação e violência (p. 89) e formação "em nível de especialização ou aperfeiçoamento para os profissionais que atuarão nas salas de recursos multifuncionais" (idem).

Outro destaque do Eixo IV é a garantia do estudo/aprofundamento da política de educação ambiental, estudo de Língua Brasileira de Sinais (LIBRAS), história da África e culturas afro-brasileiras, cultura indígena, diversidade étnico-racial, religiosa, orientação sexual e direitos humanos (p. 91).

O Eixo v trata do "Financiamento da Educação e do Controle Social", pontos essenciais do sistema educacional, porque garantem as 
condições para a implementação das políticas para além do plano retórico. Descreve uma série de medidas para melhorar e ampliar o financiamento à educação, para garantir a articulação do sistema e a transparência no uso dos recursos. Entre elas, a construção do custo aluno-qualidade (CAQ) deve levar em consideração "o conjunto de insumos necessários para o ensino-aprendizagem nas escolas públicas de educação básica”. A diversidade, as desigualdades regionais e as suas peculiaridades devem reger a priorização do acesso aos recursos. Afirma-se, também, a necessidade de destinar valores diferenciados para "os estabelecimentos que atendam crianças, adolescentes, jovens e adultos com desafios de inclusão, como pessoas com deficiência, populações do campo, populações ribeirinhas, quilombolas e indígenas". Destaca ainda que, para atender adequadamente esses grupos, é preciso, entre outros, atender "também às necessidades educacionais relacionadas à educação inclusiva” (CONAE, 2010b, p. 104).

Algumas das metas elencadas neste Eixo para o novo PNE também são essenciais para o Eixo VI. A regulamentação do setor privado e "a aplicação de recursos públicos exclusivamente nas instituições públicas de ensino" (idem, ibid., p. 107) são as que mais afetam as políticas relacionadas ao Eixo, assim como: "o congelamento das matrículas nas instituições assistenciais em 2014, extinção das mesmas até 2018 e garantia de atendimento da demanda na rede pública” (p. 115-116); a ampliação dos recursos financeiros para EJA (p. 116); e o financiamento para a inclusão de negros, povos indígenas e outros grupos e estratos historicamente excluídos do ensino superior (p. 117).

Confirma-se, assim, que a preocupação com os sujeitos e gruposalvo do Eixo vi está presente nos diferentes eixos. A explicitação e a reiteração dos direitos, assim como a constante enumeração desses grupos e das ações destinadas a lhes garantir acesso a bens e serviços sociais chamam atenção para uma presença que tende a se afirmar e a redimensionar os modos de se considerar o direito à educação. Evidencia-se, assim, a difusão de uma visão que, ao menos no plano da enunciação, admite a necessidade de trabalhar com as diferenças em todos os níveis e modalidades do ensino, de reconhecer e valorizar a diversidade, de transformar os sistemas educacionais em inclusivos, de formar professores na perspectiva da inclusão, de estudar e difundir conhecimento sobre todos os temas que dizem respeito às diferenças, de alocar recursos financeiros de maneira diferenciada, de acordo com prioridades 
pré-estabelecidas e de atender toda a demanda educacional em instituiçōes públicas. É notável essa interpenetração, particularmente em relação aos temas do Eixo VI e, em alguns casos, a duplicação de propostas, afirmações e reivindicações.

\section{Especificidades do Eixo VI}

Denominado "Justiça Social, Educação e Trabalho: Inclusão, Diversidade e Igualdade", o Eixo VI é definido no Documento Final como “(...) eixo político, prático e pedagógico das políticas educacionais (...)" (CONAE, 2010b, p. 123). O texto aponta para a incorporação dos temas relacionados no eixo à agenda da política educacional e destaca que as conquistas, em relação a estes, que se devem, em grande parte, à ação política dos movimentos sociais, são díspares e marcadas pelo contexto de desigualdade histórica no país.

Ao se referir à construção de um "sistema nacional de educação", explicita a necessidade de considerar "os temas abordados nesse eixo em sua articulação e intermediação com os outros cinco eixos anteriormente apresentados" (idem, ibid., p. 124; grifos no original). O texto reitera a universalidade de direitos, a necessidade de superar desigualdades sociais e incorporar o respeito à diversidade no sistema educacional. Orienta políticas afirmativas, emergenciais e transitórias para garantir acesso e permanência de todos nas escolas e que estas podem ser implementadas na forma de leis, programas, metas, reserva de vagas, preferência, cotas (p. 126). É destacada a importância dos movimentos sociais como "atores políticos que problematizam essa situação" e afirmada a necessidade de reconhecer o direito à diferença e de tratar "desigualmente os desiguais", o que não contradiz a necessidade de lutar contra a desigualdade social (p. 127). Conforme o documento, também é preciso "compreender a diferença como construção histórica, cultural e social" (p. 128).

As políticas devem assegurar o respeito às diferenças, o combate ao racismo, preconceito, discriminação e intolerância, além de garantir a educação inclusiva e a formação de profissional "voltada para a educação das relações étnico-raciais, educação quilombola, educação indígena, educação ambiental, do campo, das pessoas com deficiência, de gênero e orientação sexual, com recursos públicos". É preciso também 
avaliar, monitorar e aperfeiçoar as políticas de ação afirmativa, implementar políticas de pesquisa e pós-graduação sobre os temas agrupados no eixo, formular outras específicas para a construção de material didático na perspectiva da diversidade e para a inserção de pessoas com deficiência no mercado de trabalho (CONAE, op. cit., p. 129). Por fim, deve haver garantias por meio de vinculações especificadas em lei, da obrigatoriedade de apoio financeiro às políticas de diversidade, trabalho e inclusão social (idem, ibid., p. 130).

Cada um dos temas agregados no Eixo IV foi objeto de considerações em separado. A maioria delas expressa reivindicações relativas à inclusão e ao acesso e permanência de cada grupo em todos os níveis e modalidades da educação. Algumas dessas considerações são bem destacadas. Por exemplo, em relação às questões étnico-raciais, a criação de "condiçôes políticas, pedagógicas e financeiras" para a efetivação das diretrizes curriculares e leis sobre relaçôes étnico-raciais, lembrando que a existência da legislação não garante a sua implementação ou mesmo a sua eficácia.

O documento aprova a instituição do "Plano Nacional de Educação Quilombola” e propõe que se assegure a atuação de professores/ as provenientes dessas comunidades (p. 132), entre outras propostas tendentes a garantir a preservação e a valorização da sua cultura e costumes.

O tema "educação especial", dirigido à população-alvo denominada no texto como "pessoas com deficiência, transtornos globais do desenvolvimento [TGD] e altas habilidades/superdotação”, está organizado em 23 propostas que reafirmam o direito de acesso irrestrito à educação, pautado na garantia de condições para a implementação de uma "Política Nacional de Educação Inclusiva", apontando, entre outros fatores, a importância da "participação da família e da comunidade nas instituições educativas" (CONAE, 2010b, p. 133).

Destaque especial na extensão do direito à educação é dado ao atendimento desse alunado na faixa etária de 0 a 3 anos, pois "serviços de intervenção precoce, que otimizem o processo de desenvolvimento e aprendizagem", devem ser garantidos "em interface com os serviços de saúde e assistência social” (idem, ibid.).

A educação para esse alunado deve concretizar-se na escola regular, em classe comum, com atendimento educacional especializado 
Inclusão, diversidade e igualdade na CONAE $2010 \ldots$

complementar e no "contraturno". Desse modo, definida a educação especial, fica vetada a organização do atendimento escolar dessa população em classes ou escolas especiais, bem como em instituições especializadas. As demais propostas aprovadas na CONAE 2010 para a educação especial referem-se a meios e condiçôes para garantir a igualdade de oportunidades e envolvem a expansão das "salas de recursos multifuncionais" regidas por "profissionais qualificados/as", bem como a ampliação desses "profissionais especializados/as" em "escolas públicas regulares". Além destes, estão previstos nas classes comuns: "professor/a auxiliar" e, especificamente para aqueles com surdez ou surdocegueira, "intérprete/tradutor/a", "guia-intérprete" e "professor/a de LIBRAS" (CONAE, 2010b, p. 133).

Outros recursos como "transporte escolar adaptado", formação de motoristas e monitores/as para esses veículos e as "parcerias com órgãos governamentais e não governamentais" visam a garantir a acessibilidade física dos/das estudantes com deficiência e TGD. Na educação superior, especificamente, está prevista acessibilidade "nos processos seletivos e no desenvolvimento de todas as atividades que envolvem o ensino, a pesquisa e a extensão" e, ainda, "a transversalidade da educação especial, por meio de ações que promovam o acesso, a permanência e a participação dos/das estudantes", incluindo tudo que se refere a livros, materiais didáticos e pedagógicos, equipamentos e mobiliários adaptados para o público-alvo da educação especial (idem, ibid., p. 134).

Outras reivindicações para garantir condições de acessibilidade para pessoas com cegueira e surdez foram organizadas na proposta, que visa a "incluir Braille e LIBRAS no currículo da educação básica e garantir políticas públicas para o ensino de LIBRAS para os/as profissionais servidores/as" (p. 134).

$\mathrm{O}$ atendimento a esse alunado deve contar com apoios de "parcerias com órgãos governamentais e não governamentais" também para "promover (...) serviços de saúde, assistência social, justiça e trabalho"; e suas demandas educacionais devem ser contempladas por meio de "parcerias com a saúde, ação social e cidadania", que se constituam como "redes de apoio aos sistemas educacionais" (p. 134).

Os itens que abordam a formação de professores para o atendimento educacional especializado preveem "conteúdos programáticos de educação especial" que devem ser garantidos "em curso de formação profissional” (p. 134). 
Reconhece-se, assim, que não haverá inclusão efetiva sem uma política de formação que inclua questões de caráter pedagógico stricto sensu e aborde princípios e valores de acolhimento às diferenças, bem como a mudança de atitudes e estratégias de combate ao preconceito e às manifestações de discriminação.

Quanto ao atendimento escolar de surdos, este pode ser considerado um campo de tensão do Eixo VI e um aspecto em que o rumo adotado pela atual política educacional confronta a opinião da maioria dos grupos organizados da comunidade surda, já que esses grupos se opóem à matrícula de surdos na classe comum, nos primeiros anos de escolaridade, e reivindicam o direito a uma escola bilíngue, que contemple a sua especificidade linguística, garantindo-lhes a convivência com uma comunidade de usuários de LIBRAS como ambiente privilegiado também para a aprendizagem do português como segunda língua. A polarização de posições no debate é a resposta ao desconforto gerado por dois projetos ainda não concretizados em muitos sistemas de ensino brasileiro: a escola de surdos bilíngue e o ingresso e permanência desse alunado na classe comum, com garantia de acesso ao conhecimento asseverada pelos atendimentos educacionais especializados complementares (professor de/em LIBRAs e de língua portuguesa como segunda língua, e o intérprete).

Assim, das várias propostas da educação especial relacionadas aos surdos que compunham o documento da CONAE 2010 (volume II), apenas três foram confirmadas em plenário para compor o Documento Final. Estas asseguram a melhoria das condições de atendimento escolar de surdos, em primeiro lugar, pela garantia do direito de aprender LIBRAS como primeira língua, desde a mais tenra idade, e, posteriormente, a língua portuguesa, na modalidade escrita, como segunda língua. Em segundo lugar, propõe-se a oficialização da "profissão de tradutor/ a-intérprete de LIBRAS para surdos/as e do/a guia intérprete para surdos/as e cegos/as". A última proposta diz respeito à garantia de "participação dos/as educadores/as surdos/as e demais lideranças, professores/as, tradutores/as-intérpretes de LIBRAS e comunidades surdas", para que, junto com o/a gestor/a público/a, possam elaborar propostas que respondam às necessidades, interesses e projetos dessa comunidade (CONAE, 2010b, p. 134-135). Todavia, nenhuma proposta que deixasse margem à manutenção de escolas especiais ou classes de surdos foi aprovada, ficando marcada a posição pelo seu atendimento escolar em classes comuns do ensino regular. 
A consolidação de uma política pública nacional para o campo envolve "caboclos/as, indígenas, extrativistas, ribeirinhos/as, pescadores/as, quilombolas, migrantes, agricultores/as, assentados/as, sem-terra, semteto, acampados/as e outros segmentos populares dos mais diversos matizes)" (item c) (idem, ibid., p. 135). Observamos, aqui, uma interação intraeixo e uma interpenetração de temas e reivindicaçôes que se estende a outras questôes, como pode ser apreciado no seguinte extrato:

(...) garantir a permanência e ampliar o acesso a crianças, jovens, adultos, idosos/as, pessoas com deficiência, transtornos globais do desenvolvimento, altas habilidades/superdotação, entre outras residentes nas zonas rurais em todas as etapas da educação básica e superior. (Idem, ibid., p. 135-136)

Quanto à educação indígena, o Documento Final afirma a necessidade de implementar um conjunto de açóes centradas, por um lado, no reconhecimento dos povos indígenas como parte da cultura nacional e, por outro, como grupo com as suas particularidades. Estimular a criação de cursos de licenciatura indígenas nas instituiçôes de ensino superior (IES); promover o estudo dos povos indígenas nas escolas pela implementação da Lei n. 11.645/08; a utilização das línguas nativas "nas escolas indígenas que assim o desejarem"; a formação de professores/as indígenas e elaboração de propostas pedagógicas e materiais didáticos que reflitam as realidades dos povos indígenas; a profissionalização e o reconhecimento público do magistério indígena, entre outros que incluem autonomia para elaborar e desenvolver o "projeto pedagógico e calendário de cada povo indígena" e garantir a participação de membros dessas comunidades na formulação e execução da política linguística (p. 140-141).

As referências à educação ambiental destacam a necessidade de "garantir, por meio de recursos públicos, a implementação e acompanhamento da Lei da Política Nacional de Educação Ambiental (Lei n. 9795/1999)" e enfatizam a introdução da "discussão sobre educação ambiental na política de valorização e formação de profissionais da educação", assim como a implantação de políticas públicas e programas de educação ambiental na educação básica, profissional, tecnológica e superior (p. 141) e:

(...) a oferta de ensino médio articulado à formação técnica profissional nas áreas agroflorestal, ecológica, de sociedade sustentável para a elaboração e 
gestão de projetos de fortalecimento comunitário nas reservas extrativistas, territórios indígenas, comunidades quilombolas e comunidades tradicionais. (p. 142)

$\mathrm{O}$ entrelaçamento dos diferentes temas que compóem o Eixo VI torna-se evidente em relação ao meio ambiente, já que a questão está vinculada a todos os grupos e participantes dos processos educativos. A maior parte dos itens diz respeito à difusão da educação ambiental em todos os níveis e modalidades do ensino.

Os itens relacionados a gênero e à diversidade sexual abordam a introdução da discussão desses temas na política de valorização e formação dos profissionais da educação e em todos os níveis do ensino e áreas do conhecimento como disciplina obrigatória. Entre as medidas listadas encontram-se: formular critérios de avaliação de livros didáticos que eliminem as obras preconceituosas, discriminatórias e contrárias aos direitos humanos; ampliar a oferta de programas de formação, extensão, especialização, mestrado e doutorado, que abordem a temática nas IES públicas, "visando superar preconceitos, discriminação, violência sexista e homofóbica no ambiente escolar" e o fomento à pesquisa , assim como o desenvolvimento de material didático e programas de formação que contemplem tanto a promoção da saúde e a prevenção de doenças de transmissão sexual, alcoolismo e drogas, como as questôes de gênero. Também aborda a inserção, na proposta pedagógica, de questões relacionadas à violência doméstica e o "encaminhamento dos casos notificados/ denunciados para a rede de proteção". Ainda, o Ministério da Educação (MEC) deve assegurar recursos financeiros para implementar o "Projeto Escola sem Homofobia” em toda a rede de ensino. Açôes específicas devem colaborar para a ampliação do acesso e permanência na educação de "grupos específicos como mulheres não alfabetizadas, ou com baixa escolaridade, profissionais do sexo, pessoas em situação de prisão e pessoas travestis e transexuais" e "promover a formação das mulheres jovens e adultas para o trabalho, inclusive nas áreas científicas e tecnológicas, visando reduzir a desigualdade de gênero nas carreiras e profissóes" (CONAE, 2010b, p. 143-146), entre outros.

No caso de crianças, adolescentes e jovens em situação de risco, o documento prevê "(...) o cumprimento dos princípios do Estatuto da Criança e do Adolescente (ECA)"; a promoção de políticas de saúde e educação para o atendimento a essa população e para apoiar o trabalho dos 
professores que atuam junto a ela. É mencionada também a necessidade de políticas "judiciais, que assegurem o fluxo contínuo entre o atendimento imediato da criança ou adolescente e de sua família e seu retorno para a escola". Deve ser inserida "a discussão de práticas que garantam os direitos e deveres de crianças e adolescentes" em todos os níveis e modalidades do ensino. A implantação de linhas de pesquisa para o estudo dos temas relacionados, com o objetivo de ajudar os professores a lidar com os problemas na sala de aula, é também abordada, assim como a necessidade de promover a presença da juventude em suas diversas manifestaçōes, modos de participação, comportamentos e linguagens nas escolas, alem da ampliação da educação "aos/as adolescentes que cumprem medidas socioeducativas em regime fechado" (idem, ibid., p. 147).

A "formação cidadã e profissional" deve, segundo o Documento, garantir o "direito de acesso da adolescência e juventude ao ensino médio"; "consolidar a [sua] expansão"; contribuir para o desenvolvimento, atendendo a demanda crescente por formação; garantir a pesquisa e a extensão para "o desenvolvimento de soluçōes técnicas e tecnológicas" que beneficiem a comunidade; "consolidar a oferta do nível médio integrado ao profissional, bem como a oferta de cursos superiores de tecnologia, bacharelado e licenciatura", e realizar, no âmbito da educação profissional, açôes de educação especial que ampliem as oportunidades de formação, participação social e no mundo do trabalho (p. 147-148).

Da mesma forma, a "educação de jovens e adultos" (EJA) requer a consolidação de uma política que garanta a "formação integral", que envolve a alfabetização e as demais etapas da escolaridade. Assim, a EJA deve estar pautada pela "inclusão e qualidade social" e, do ponto de vista da gestão e do financiamento, deve estar em igualdade de condições em relação às "demais etapas e modalidades da educação básica" e deve estar presente, também, na "implantação do sistema integrado de monitoramento e avaliação". A "idade mínima de 18 anos para exames de EJA" deve ser considerada e garantido "o atendimento de adolescentes de 15 a 17 anos" pelo ensino regular, por meio de práticas voltadas para esses alunos, "com possibilidade de aceleração de aprendizagem e a inclusão de profissionalização (...)". O Documento Final aponta também para a consolidação de "uma política de formação permanente" destinada aos professores desse nível de ensino, que devem ser licenciados/as.

As ações de educação especial devem ampliar ao seu público-alvo de jovens e adultos as "oportunidades de escolarização, a formação para 
a inserção no mundo do trabalho e a efetiva participação social". Entre estas, deve ser ofertada "EJA diurno" a estudantes com "necessidades educativas especiais e/ou deficiência, multideficiências, transtornos globais do desenvolvimento, altas habilidades/superdotação, surdos/as", assim como "o acesso a oficinas de preparação para o trabalho". A oferta de EJA em horários alternativos ao diurno deve ser garantida a todos/ as os/as estudantes. A implantação desta modalidade nas escolas indígenas é outro destaque, assim como a assistência a estudantes com dificuldades de aprendizagem e a oferta de recursos materiais e profissionais para o atendimento específico das necessidades educativas especiais (p. 149). Alem disso, deve ser ampliado "o apoio técnico às secretarias estaduais e municipais de educação, movimentos sociais e populares que atuam com EJA", visando à "melhoria da qualidade da educação oferecida a jovens e adultos". Outros itens a serem destacados são: a garantia de condiçôes de funcionamento, financiamento e recursos ao "programa Brasil Alfabetizado"; a oferta de atendimento educacional a migrantes; a garantia de "ações afirmativas de gênero e geração de trabalho e renda voltadas para os usuários da EJA". As políticas para esta modalidade devem contemplar "a intersetorialidade, controle social, concepções de EJA, formação de educadores/as, aspectos didático-pedagógicos, gestão pública e dados da EJA”. Estas dimensões são detalhadas no documento (CONAE, 2010b, p. 148-160).

\section{Perspectivas para o Plano Nacional de Educação}

Um novo Plano Nacional de Educação será elaborado a partir das propostas aprovadas e sistematizadas no Documento Final da CONAE 2010, para viger no período de 2011-2020. O Plano de 2001 (PNE/01) teve uma tramitação conturbada e foi criticado, principalmente, por não prever a garantia de financiamento às metas então formuladas (Saviani, 2004, 2007), o que o caracterizou como uma "carta de intenção" (Valente \& Romano, 2002). O PNE/01 aborda de forma desigual os temas hoje agrupados no Eixo vi do Documento Final, pois estes aparecem no capítulo "Modalidades de ensino", que, em comum com o documento da CONAE, tem EJA, "Educação tecnológica e formação profissional", tratada em 2010 por "Formação cidadã e profissional", bem como "Educação especial" e "Educação indígena"; e a estas se soma, em relação a 2010, a "Educação a distancia". Entretanto, o PNE/ 01 não aborda a "educação do campo", as "relações étnico-raciais", a 
Inclusão, diversidade e igualdade na CONAE $2010 \ldots$

"educação quilombola", de "gênero e diversidade sexual", nem a "educação ambiental", de "crianças, adolescentes e jovens em situação de risco", "educação prisional", como matérias em separado (CONAE, 2010b). Constata-se, assim, que esses temas ganharam visibilidade e maior atenção da sociedade na última década.

O PNE/01 contempla, nos seus diferentes capítulos, a temática do Eixo VI. Assuntos como a necessidade de adequação do espaço, instalações, mobiliário, equipamentos e materiais pedagógicos aos alunos com necessidades educacionais especiais constam no capítulo sobre Educação Infantil (Brasil, 2001, p. 28). É mencionada também a colaboração com outros setores da sociedade (saúde, assistência social e organizações não governamentais) para oferecer programas de orientação e apoio aos pais, assistência jurídica, financeira e de suplementação alimentar "nos casos de pobreza, violência doméstica e desagregação familiar externa" (idem, ibid., p. 30).

Em relação ao ensino fundamental, constam referências similares vinculadas ao atendimento de alunos com necessidades educacionais especiais, além de outras que remetem à manutenção e consolidação do programa de avaliação do livro didático e, dentro dele, a formulação de "critérios à adequada abordagem das questóes de gênero e etnia e a eliminação de textos discriminatórios ou que reproduzam estereótipos acerca do papel da mulher, do negro e do índio", à provisão de transporte escolar as zonas rurais, à "previsão de formas mais flexíveis de organização escolar para a zona rural, bem como a adequada formação profissional dos professores (...)" e à educação ambiental, tratada como tema transversal e prevista na Lei n. 9.795/99 (Brasil, op. cit., p. 40-43).

Quanto ao ensino médio, as metas do PNE/01 apontam: “(...) o atendimento da totalidade dos egressos do ensino fundamental e a inclusão dos alunos com defasagem de idade e dos que possuem necessidades especiais", a adaptação dos prédios para a garantia do acesso desses alunos, a adequação do ensino noturno ao aluno trabalhador e a educação ambiental (idem, ibid., p. 51-54).

No que se refere ao ensino superior, com a mesma fórmula utilizada para os demais níveis de ensino, recomenda-se observar "as metas estabelecidas nos capítulos referentes à educação a distancia, formação de professores, educação indígena, educação especial e educação de jovens e adultos" (p. 68). 
Em suma, parte dos temas do Eixo VI também está presente no PNE/01, mas estes não receberam o grau de desenvolvimento e detalhamento que se observa no Documento Final (CONAE, 2010b). A atenção concedida por este às dimensóes que dizem respeito ao papel do Estado, ao controle social, à fiscalização, ao financiamento, à gestão democrática, à avaliação, à participação dos movimentos sociais, das comunidades e das famílias nas diversas instâncias envolvidas com os sistemas de educação, à formação de professores para atuar nos diferentes níveis e modalidades, trabalhando na perspectiva da diversidade e da inclusão escolar e contra qualquer tipo de discriminação, retoma, inclusive, aspectos levantados no Plano Nacional de Educação - Proposta da Sociedade Civil (CONED, 1997).

Contudo, o destaque dos temas do Eixo VI na CONAE 2010 acontece de um modo singular, que reforça as diferenças históricas entre os grupos focalizados em relação à educação, à inclusão social e ao trabalho. Não se vislumbram grandes novidades nas propostas de políticas para o Eixo. A maior parte delas expressa reivindicações já conhecidas por sua explicitação em vários canais (legislação brasileira e outras fontes) e, de um modo geral, conclama a atenção do Estado e da sociedade para si. São grupos, em sua maioria, preteridos historicamente, que há muito vêm se organizando para reivindicar a implantação e o incremento de políticas que garantam o direito à educação e à cidadania.

Nos demais eixos do Documento Final, é passível de destaque a presença maciça de referências aos temas do Eixo VI e a nomeação constante e reiterada dos grupos que o compóem. O Documento Final, em discussão, revela a difusão, a incorporação - em nível do discurso - e certo consenso em relação às ideias inclusivas. Este consenso é reforçado pela permanência ou reiteração de reivindicações que constavam no PNE de 2001. O discurso inclusivo e a reivindicação de direitos dos vários grupos têm hoje uma penetração e uma difusão que, esperamos, sejam duradouras e indicativas de uma verdadeira vontade política de enfrentamento dos complexos problemas educacionais que ainda se apresentam no Brasil.

A tentativa de garantir, para cada grupo, uma política de abrangência nacional (plano nacional de educação quilombola, política nacional de educação para o campo, política de educação ambiental, entre outras) indica - do nosso ponto de vista - uma estratégia de diferenciação 
que se apresenta como forma de os grupos verem contempladas as suas necessidades particulares e especificidades, em muitos casos, pela primeira vez na história do país.

O detalhamento das medidas e as propostas de transversalidade extra e intraeixo se apresentam, por sua vez, como indícios de uma concepção que entende o sucesso das políticas educacionais dirigidas a cada grupo como uma função de medidas que envolvem tanto os outros eixos (papel do Estado, qualidade, gestão, formação de professores e financiamento), como os próprios temas do Eixo VI (educação especial para EJA ou para a educação no campo; política de alfabetização e escolarização de mulheres, profissionais do sexo, travestis, transexuais; educação profissional articulada à educação ambiental etc.) e como função da intersetorialidade (ações articuladas com a saúde, o transporte, o trabalho).

A partir das considerações anteriores, concluímos que, em relação aos temas do Eixo VI, o novo Plano Nacional de Educação terá como tarefas principais articular as reivindicações dos grupos historicamente preteridos, de modo a integrar os esforços na direção de atender às suas particularidades, sem pulverizar recursos e duplicar açôes. $\mathrm{O}$ novo Plano reiterará demandas já postas em algumas áreas, mas esperamos também que se constitua como instrumento propulsor da concretização de objetivos educacionais longamente acalentados pela sociedade brasileira.

Recebido em julho de 2010 e aprovado em agosto de 2010.

\section{Nota}

1. O Programa de implantação de Salas de Recursos Multifuncionais está regulamentado pelo Edital n. 01, de 26 de abril de 2007.

\section{Referências}

BRASIL. Lei n. 10.098, de 19 de dezembro de 2000. Estabelece normas gerais e critério básicos para a promoção da acessibilidade das pessoas portadoras de deficiência ou com mobilidade reduzida, e dá outras providências. Diário Oficial da União, Brasília, DF, 20 dez. 2000. 
BRASIL. Conselho Nacional de Educação. Câmara de Educação Básica. Parecer $n$. 13, de 24 de setembro de 2009. Brasília, DF: CNE/CEB, 2009a.

BRASIL. Conselho Nacional de Educação. Câmara de Educação Básica. Resolução n. 4, de 2 de outubro de 2009. Brasília, DF: CNE/CEB, 2009b.

BRASIL. Ministério da Educação. Plano Nacional de Educação (PNE). Brasília, DF: MEC/INEP, 2001.

BRASIL. Ministério da Educação. Secretaria de Educação Especial. Politica Nacional de Educação Especial na Perspectiva da Educação Inclusiva. Brasília, DF: MEC/SEESP, 2008a.

BRASIL. Ministério da Educação. Secretaria de Educação Especial. Decreto n. 6.571, de 17 de setembro de 2008. Brasília, DF: MEC/sEEsP, 2008b.

CONFERÊNCIA NACIONAL DE EDUCAÇÃO (CONAE), 2010, Brasília, DF. Construindo o Sistema Nacional articulado de Educação: o Plano Nacional de Educação, diretrizes e estratégias; Documento-Base. Brasília, DF: MEC, 2010a. v. 1-2.

CONFERÊNCIA NACIONAL DE EDUCAÇÃO (CONAE), 2010, Brasília, DF. Construindo o Sistema Nacional articulado de Educação: o Plano Nacional de Educação, diretrizes e estratégias; Documento Final. Brasília, DF: MEC, 2010b. 164p. Disponível em: <http:// conae.mec.gov.br/images/stories/pdf/pdf/documetos/documento_ final.pdf>

CONGRESSO NACIONAL DE EDUCAÇÃO (CONED), 2., 1997, Belo Horizonte. Plano Nacional de Educação: a proposta da sociedade brasileira. Belo Horizonte, MG, 1997.

SAVIANI, D. Da nova $L D B$ ao novo Plano Nacional de Educação: por uma outra política educacional. 5. ed. Campinas: Autores Associados, 2004.

SAVIANI, D. O Plano de Desenvolvimento da Educação: análise do projeto do MEC. Educação \& Sociedade, Campinas, v. 28, n. 100, p. 1231-1255, out. 2007. 
Inclusão, diversidade e igualdade na CONAE $2010 \ldots$

VALENTE, I.; ROMANO, R. PNE: Plano Nacional de Educação ou carta de intenção? Educação \& Sociedade, Campinas, v. 23, n. 80, p. 97-108, set. 2002. 